\title{
JOHN COPLANS: O CORPO ESCULTÓRICO
}

\section{Magda Rebello ${ }^{1}$}

\section{Graça Magalhães ${ }^{2}$}

\begin{abstract}
Resumo: O artigo refere-se à representação do corpo como um objeto sem identidade e simbolismos nas obras do fotógrafo John Coplans, onde ele nos faz questionar a relação do autorretrato e o papel do significado do corpo em suas fotografias. O artista e espectador relacionam-se com o corpo na imagem, e a ideia de um corpo escultórico. A base metodológica da pesquisa e estudo teórico sobre o tema, influências, paradigmas, conceitos e referências de autores, como: Viviane Matesco, Roland Barthes, Vilhem Flusser, Philipe Dubois, Annateresa Ferris entre outros; a serem discutidos no decorrer do artigo. Como resultados, espera-se uma contribuição aos estudos da arte contemporânea sobre a relação do corpo (conteúdo) com o objeto de arte (forma) e imagem.
\end{abstract}

Palavras-chaves: Corpo. Imagem. John Coplans. Autorretrato.

\section{INTRODUÇÃO ${ }^{3}$}

A representação do corpo como um objeto sem identidade nas obras de John Coplans, nos faz questionar a relação do autorretrato e o papel do significado do corpo em suas fotografias. O "corpo é um invólucro" (Gil, 1997, p.16) deste ser, o artista, que o utiliza como artifício para representar a relação homem versus tempo, assim como o corpo versus forma. Nas obras de John Coplans é notável a referência do imaginário da história da arte. O estudo da representação tradicional dos gregos e clássicos em suas poses e formas recriando uma nova maneira de representação do corpo. Através das referências artísticas, principalmente dos mestres da escultura, o artista constrói o corpo através de fragmentos de ima-

\footnotetext{
1 Mestre em Criação Artística Contemporânea pela Universidade de Aveiro. E-mail: magdarebello@yahoo. com.br

2 Professora Doutora na Universidade de Aveiro. E-mail: gracamag@ua.pt

3 Agradeço a Denise Cathilina que em suas aulas apresentou-me meus grandes mestres da fotografia e desde então John Coplans inspira-me.
} 
gem e registros obtidos através da imagem técnica com intenção de retratar a matéria que consolida este corpo. Esta construção da imagem corpórea cria uma nova referência de identidade para aquele corpo. Com estas imagens, o artista e espectador passam a ter uma relação com o corpo na imagem, não apenas, com a imagem do corpo. Buscando assim novos meios de leitura e concepção desta imagem.

John Coplans (1920-2003), foi pintor e editor da revista ArtForum durante anos, este lado como teórico em sua vida fez despertar outras visões dentro das artes, particularmente a fotografia. Seu trabalho como pintor expressionista abstrato, garantiu-lhe um conhecimento técnico para desenvolvimento da sua pesquisa como fotógrafo. As suas fotografias foram expostas e publicadas diversas vezes, tornando-se parte de coleções de grandes museus, como o MoMA em Nova York. O seu interesse por fotografia ocorre a partir do ensaio Brancusi as photographer, no momento que ele observa a relação entre a fotografia e escultura. Coplans comenta a maneira por meio da qual Brancusi, diferentemente de Rodin para quem a fotografia era uma técnica para documentar suas obras, explora na fotografia os elementos comuns que esta tem com a escultura: luz, espaço e temporalidade" (Martinéz, 2009, p.187), com estes parâmetros ele consegue desenvolver uma pesquisa acerca do autorretrato usando o nu masculino de um corpo envelhecido como "uma figura arcaica, que fosse ele e não fosse ele ao mesmo tempo" (Fabris, 2004, p.165), esta questão do "ser ou não ser" é discutida a partir do momento que utiliza o termo autorretrato, pois se este é autorretrato porque não se auto referenciar?” Neste caso, há uma sobreposição de papéis: modelo e fotógrafo são a mesma pessoa. O fotógrafo vê por meio de seu conhecimento as possibilidades que o processo lhe oferece e as condições em que o trabalho deverá ser visto para construir uma imagem que, mais do que as marcas do retratado, expressa os valores artísticos que norteiam suas escolhas" (Martinéz, 2009, p.176), ao desenvolver os dois papéis fotógrafo e modelo, retira a intimidade do registro e dos signos que denominam a identidade, este jogo de ser ou não ser Coplans faz com que o espectador tente codificar o "eu" registrado,

Pode influenciar nosso modo de ver seu trabalho como o resultado da intimidade com os meios e processos de que dispõe para "construir" um retrato de si mesmo. Na intimidade, restrita ao estúdio, produz-se a visão mais objetiva de seu próprio corpo, registrada pelo equipamento fotográfico (Martinéz, 2009, p.176). 
Porém, o que vemos como pesquisa do artista é tornar este corpo um objeto possível de diversas interpretações, ou mesmo, torná-lo apenas um objeto, como se fosse algo inanimado, uma escultura sem identidade. A fotografia é direta, assim como o olhar do fotógrafo sobre seu próprio corpo. "A obra que deliberadamente realiza, expondo seu próprio corpo, evidencia uma opção de se auto-retratar como quem não quer não ser visto" (Martinéz, 2009, p.184).

\section{O CORPO E O RECONHECIMENTO DO EU}

Quando se observa uma fotografia de John Coplans automaticamente fazemos a leitura do significado daquela imagem: é um corpo, ainda mais que este se encontra nu. Esta nudez não nos causa uma inquietação ou constrangimento ao observá-la "Existe uma grande distância entre o olhar indiferente aos outdoors com anúncios de lingerie feminina, em áreas urbanas, e o olhar que, na galeria, se detém na contemplação do corpo de um homem nu" (Martinéz, 2009, p.195). A galeria, como instituição cria uma atmosfera que desqualifica o ato de desejar no âmbito sexual, enquanto a nudez sugere o estado de quem está desprovido de vestes e o correspondente embaraçoso dessa situação, o nu não projeta em nosso espírito a imagem de um corpo tolhido e indefeso, mas daquele equilibrado, desabrochado e seguro de si mesmo: o corpo remodelado (Matesco, 2009, p.26), isto é, um corpo nu que representa uma singularidade, um ser, não se trata de um corpo visto, mas sentido.

O corpo nu é exaustivamente utilizado como forma maleável, subjugada
à composição, sem produzir uma intimidade sentimental que particu-
larizaria a exposição do indivíduo. (...) Ainda que veja as formas de seu
corpo nu, o espectador não tem acesso ao universo interior, emocional
ou psicológico, de Coplans. Expõe a imagem de uma situação comum, e
aí está o ponto de partida para a identificação do espectador (Martinéz,
2009, p.193).

Além de ser um corpo, é um corpo nu masculino, o que cria um outro significado sobre este corpo: é um homem. Chegamos a esta conclusão, sem ver órgãos sexuais ou a cabeça do corpo fotografado, pois os signos que o definem, "aqueles que Bourdieu denomina os "órgãos nobres da apresentação": face, fronte, olhos, boca” (Fabris, 2004, p.158), não estão registrados nas imagens. Sabemos também, que é um autorretrato pois ele mesmo faz os registros e posa para as fotografias afirmando-o em alguns títulos das fotografias. Em nenhumas de suas fotografias há o registro do rosto, sabendo que o rosto é o signo que dá identidade 
ao corpo, que designa a pessoa como indivíduo, neste caso, por ser um corpo sem rosto, ele deixa de ser indivíduo e se torna objeto. É como se perdesse sua essência, o "eu" enquanto Coplans torna-se um objeto que significa o corpo. Porém é possível criar um "eu" das imagens ao observá-las:

seus autorretratos acéfalos, destituídos justamente daqueles elementos nos quais se condensa de imediato a identidade social? (...), mas ambos abrem a possibilidade de discutir a noção de autorretrato e, logo de identidade, a partir de uma visão corriqueira" (Fabris, 2004, p.158).

Ou seja, sem a identidade retratada pelo rosto, a imagem perde o significado do autorretrato, mas não deixa de ser corpo. Neste caso Coplans deixa de ser Coplans, é a representação de um corpo, sem identidade para quem o observa. "Aqui o sujeito moderno é definido por sua própria definição: o corpo enquanto forma torna-se a morada do eu como espelho de reconhecimento" (Matesco, 2009, p.31), como espelho do "eu", na foto é o reconhecimento do espectador que dará a significado à imagem. $\mathrm{O}$ indivíduo constrói uma identidade imaginária e ilusória; atesta a existência de uma unidade que a própria superfície do espelho coloca em crise, ao criar uma cisão entre o "eu" que se apresenta no reflexo e o eu que o percebe (Fabris, 2004, p. 78).

Como se as fotografias fossem espelhos de quem as observa, conduzindo o espectador ao reconhecimento na imagem, ou seja, projetando o próprio "eu" sobre a imagem. Pelo fato do objeto fotográfico não ter identidade, vemos que é um homem, mas pode ser qualquer homem, não há registro do eu -"o "eu" encontra- se por detrás de um rosto" (Gil, 1997, p. 154), como tal o corpo acéfalo perde a identificação, apenas se torna uma imagem técnica, entendemos que é de gênero masculino ao observar características e elementos de um corpo masculino na imagem.

\section{A MUDANÇA DO SIGNIFICADO}

Ao retratar seu corpo nu em diversas poses fragmentadas, quase que abstratas, sempre buscando um enquadramento não habitual o trabalho plástico resulta como montagem. As figuras de Coplans não são compostas por partes, mas sim por fragmentos. O corpo é desmembrado em enquadramentos independentes, de partes que compõem imagens, reunidas por um olhar que vê 
um movimento corporal coerente e dinâmico. A técnica, ou procedimento plástico, é a montagem (Martinéz, 2009, p.192). Com isso, Coplans consegue ir além do significado mimético do corpo. "A constante presença de um corpo fragmentado é uma metáfora da perda de totalidade que caracteriza a modernidade. O homem é efêmero, um fragmento do mundo contingente e errante" (Matesco, 2009, p. 33-34). Assim, Coplans além de falar de identidade nos fala de tempo e de finitude. É um corpo transitório, porém a imagem técnica é atemporal diferente do corpo passageiro. "Um corpo que transita, um corpo que está apenas de passagem" (Bruno, s/d). Essa passagem transitória se refere ao tempo, a idade, a vida e a morte, às imagens de um corpo envelhecido e desprovido de vaidade.

O artista busca retratar o tempo, que é algo abstrato e subjetivo, através da metáfora, das rugas apresentadas em seu corpo, da flacidez, das marcas na pele, que são os signos do corpo, "o homem distribui signos segundo os cortes que opera no real, classifica, reagrupa, define. Pode assim identificar os seres e as coisas, estabelecendo relações precisas entre os significantes e os significados" (Gil, 1997, p.16). Esta busca por significação também é uma busca pelo reconhecimento do objeto retratado (assunto) e o "eu" (seja do assunto ou espectador) ali apresentado. Os signos desenvolvem-se em relação aquilo que é apresentado, pois existe um referencial de conhecimento do que é visto. Neste caso o espectador entende o que é retratado (significante): o corpo inteiro ou fragmentos. Estes somados, reagrupam o significado de corpo representado na imagem: "corpo é corpo, porém as estruturas apresentadas vão além desta significação" (Matesco, 2009, p. 33-34). A “nova” significação por ele obtida advém da utilização das técnicas fotográficas, do seu processo criativo e apresentação final (montagem) das imagens técnicas. Com estes recursos técnicos Coplans desenvolvia sua pesquisa em fotografia da seguinte forma: primeiro, fotografava em instantâneos e depois fazia uma nova impressão em grande formato. Esta atitude faz com que o corpo seja trabalhado em dois formatos: num primeiro momento em uma escala bem menor que o real, e o segundo momento numa impressão maior que o referencial (neste caso o seu corpo).

As formas diagonais em relação à ortogonalidade dos formatos, o espaço vazio do fundo em relação à textura da pele e a descontinuidade das linhas de contorno, constroem uma obra que põe em relação qualidades contrárias como mutabilidade / permanência, fragmentação/unificação, ilimitado/limitado, duratividade /pontualidade, particularidade/ generalidade, antiguidade/contemporaneidade, indistinto/distinto, contínuo/descontínuo" (MARTINÉZ, 2009, p.192). 
Os quesitos concretos como textura, contorno, forma, tamanho, versus os abstratos como tempo, por exemplo, são questionados a partir do olhar. Observando além do invólucro, e encontrar, ou melhor, sentir o punctum (Barthes, 1984, p. 47), que para Barthes chega a ser uma passagem de um vazio, um olhar através da imagem, ou ver além daquilo que está registrado, aquilo que punge. Neste caso, o punctum pode ser uma ruga, uma dobra na pele, algo que difere e chama a atenção ao ponto de conseguir mudar o significado da imagem. Com isso observamos que este corpo possui matéria: tem linhas curvas, densidade, volume e textura, isto é, tem forma, tornando o corpo o objeto da imagem.

As decisões tomadas pelo fotógrafo não visam apenas a composição coerente dos fragmentos enquadrados, mas sim uma composição equilibrada de formas, texturas e tonalidades de cinza. Coplans não é o corpo nu que fotografa, transformado em objeto. Cada enquadramento é único e não contribui para a montagem de uma imagem contínua. A justaposição e o enquadramento são evidenciados, o que nos leva a considerá-los como estratégia compositiva essencial para que a sequência de imagens tenha temporalidades e espacialidades dilatadas. O resultado é um retrato da situação do fotógrafo que, no estúdio, é retratista e torna-se cada vez mais comprometido com o conhecimento cumulativo que a visão do real através da lente lhe proporciona, a ponto de não poder selecionar o melhor enquadramento. Em vez de síntese, análise da forma.

\section{O CORPO ESCULTÓRICO}

As fotografias de Coplans apresentam uma tridimensionalidade como se fossem uma escultura. Como um corpo é capaz de se tornar uma escultura através de um registro em duas dimensões? Quando pensamos numa estátua pensamos em materiais como: mármore, argila, bronze, madeira entre outros. O corpo representado por Coplans faz alusão a esses materiais, a pele ganha densidade, as rugas ganham profundidade, o corpo representa o volume da escultura. Coplans utiliza a luz, contrastes, saturações consideradas ideais para que o resultado imprima essa tridimensionalidade, um volume quase escultórico das formas.

Segundo Robert Feintuch, a qualidade permanente, e monumental do bronze. Para isso não concorrerem a escala não ampliada das imagens, mas também a qualidade gráfica perseguida por Coplans, que confere 
aos cinzas a tarefa de criar passagens tonais que acentuam a elegância e a firmeza da composição. (...) apresenta-se como uma matéria intensamente condensada e portadora de qualidades monumentais em sua simplicidade formal, realçada pelos contrastes de tonalidades escuras dos fragmentos corporais em um fundo cinza-claro (Fabris, 2004 p.163).

Nas fotografias de Coplans, existe uma relação empírica entre o corpo, ali representado, e a referência escultórica. Esta é uma referência consciente, uma memória do próprio corpo, sendo representada nas poses.

Coplans desmembra a temporalidade da exposição do objeto ao material fotossensível em imagens autônomas e evita a escolha do ângulo mais expressivo. "Cada imagem em um grupo de fotografias tem seu potencial aurático rarefeito, minimizado, em uma serialização que nos diz mais sobre o mesmo objeto. A composição geral apresenta um tratamento homogêneo da forma: luz, direções e enquadramentos dos fragmentos de imagem fazem do "flagrante original" um conceito irrelevante. No conjunto, cada fotografia de uma pose não é tratada como se fosse única, mas sim codependente da anterior e da subsequente." (Martinéz, 2009, p.186)

Estas poses, resultam de linhas sinuosas que ganham destaque na imagem. A autonomia destas poses cria uma ligação entre umas e outras, através do movimento ali registrado. O movimento do corpo, não é um movimento físico, mas sim, um movimento de linhas que constroem a imagem.

O registro do movimento aparece nas tensões dos músculos, agachamento do corpo apresentados através dos joelhos e cotovelos. "Mas esse movimento é apenas uma ideia de movimento, o corpo encontra-se estático e o que faz com que ele ganhe esse movimento é a leitura de quem vê "(Martinéz, 2009, p.184). A pele e membros ganham um outro significado através das poses e do jogo de luz. Cabe a nós dar significado às formas, através da memória e intuição, pois não há intenção do artista de citar obras existentes apesar das referências no estudo das poses.

Coplans, ao comentar a obra de Constantin Brancusi, define o que a fotografia e a escultura têm em comum: luz, espaço e temporalidade. Essa aproximação nos serve como base para compreender a relação aparentemente paradoxal entre descontinuidade e unidade na obra de Coplans e na de outro escultor, Auguste Rodin, sobretudo as esculturas 
em bronze realizadas em seus últimos anos de trabalho. Rodin também passou a valorizar o fragmento, em detrimento da parte. Sem perder de vista a expressão de um movimento global da figura, percebe que este é a soma de todos os ângulos em uma relação dinâmica que é produto da descontinuidade tensionada pela independência das partes. Durante uma visita ao Museu do Louvre, Rodin avalia a unidade formal obtida por Michelangelo na execução de um de seus escravos (Martinéz, 2009, p.184).

Ao analisar estas obras, técnica e conceitualmente, Coplans atinge o seu objetivo de tornar o corpo um objeto, ou uma escultura. Na série Frienze, No 2 (Figura 3) vemos uma imagem formada por 12 fotografias, 4 trípticos justapostos. O corpo encontra-se em pé e parece que está girando em torno de si mesmo. Cada fotografia funciona como quadrante de uma imagem, cada quadrante registra uma parte do corpo. Se analisarmos uma por uma teremos fragmentos da imagem, mas ao analisarmos o conjunto podemos ver uma imagem criando um movimento de curvas que desenham as formas do corpo. As poses ali registradas remetem-nos para esculturas gregas ou renascentistas, para o movimento do corpo, girando em torno de si próprio. Paradoxalmente, este corpo que parece estar girando, está, ao mesmo tempo, estático. Esta justaposição dá uma nova referência ao corpo, um novo significado.

A decomposição do corpo em fragmentos é a estratégia de Coplans para a composição do movimento. "Em vez da linearidade da sequência do movimento, em que os quadros progressivamente perdem a semelhança com seus antecedentes, Coplans opta pela simultaneidade" (Martinéz, 2009, p.187).

Cria-se uma atmosfera de objetização do corpo. Apesar da nudez do corpo desqualificar o desejo, tornando-o desumanizado, lançamos um olhar mais apurado ao observar as rugas, por exemplo, na obra Back of Hand (Figura 1), a mão contém a flacidez da pele, as rugas criam linhas sinuosas e volumosas. Os dedos dobrados e unidos, unificam a matéria, parecem colados formando um objeto. Nesta imagem a pele parece descolar do corpo, lembrando algo flexível, maleável como um tecido. Essa ideia de tecido remete-nos para as representações de estátuas, gregas e clássicas, por exemplo, com todos os seus volumes, curvas e sinuosidade. Como podemos observar em Back with Arms Above (Figura 2), um corpo de costas e sem cabeça, sobre os ombros as duas mãos fechadas, a abstração e recorte da imagem remete-nos, de novo, para a escultura. As costas parecem um retângulo com dois nós acima. A forma, traduzida pelo peso do retângulo, é maior que o significado das costas, em si. 
A imagem das costas é o contraponto da figura do torso, explorada nas obras de escultores que atribuem a esta parte do corpo uma concisão vital. Brancusi explora o torso como um tema, tanto na escultura quanto na fotografia, para realizar uma síntese geométrica, equilibrada e simétrica. Se retrocedermos um pouco mais, teremos que considerar um percurso de Rodin a Coplans, ou se quisermos ser ainda mais rigorosos, das esculturas mutiladas da Antiguidade Clássica e Michelangelo a Coplans (MARTINÉZ, 2009, p.187).

Coplans constrói a ideia de escultura no corpo retratado. O autorretrato é o material utilizado. Não há nada mais cheio de significado que o próprio corpo, a atitude de coisificá-lo é atingida através da qualidade compositiva e técnica. O alcance da forma, através de algo material, mas sem identidade, significa a representação do corpo, tornando-o objeto escultórico.

\section{CONCLUSÃO}

Convidando-nos a admirar um corpo além do corpo, não há intenção do artista de mostrar sua identidade social ou intimidade pessoal, mas sim mostrar que se pode ver além daquilo representado em suas fotografias. Apesar de ser o corpo do artista, através das características compositivas: linhas de contornos, linhas diagonais, volume e texturas, esse corpo perde a ideia de pertença através do meio técnico: jogos de luz e sombra. Coplans intensifica as composições para destacar as formas do objeto. A abstração do corpo, tornando-o objeto na imagem. A imagem é constituída por fragmentos que justapostos corporizam o real, dando a ele um reflexo. A ausência perspéctica destas imagens fogem à relação comum dos objetos no espaço. O objeto representado é um corpo acéfalo, sem identidade, que busca um reconhecimento no espectador, o significado procura a interpretação daquele que o vê. As fotografias de John Coplans, buscam questionar a relação homem-objeto admitindo que a escultura é estática e sem vida, o corpo busca a representação. Em suas fotografias o artista recria os limites do corpo e da fotografia, procura o movimento através da imagem estática, registra o tempo e a vida abstraindo e amplificando o seu corpo, tornando-se gigante diante do olhar. 


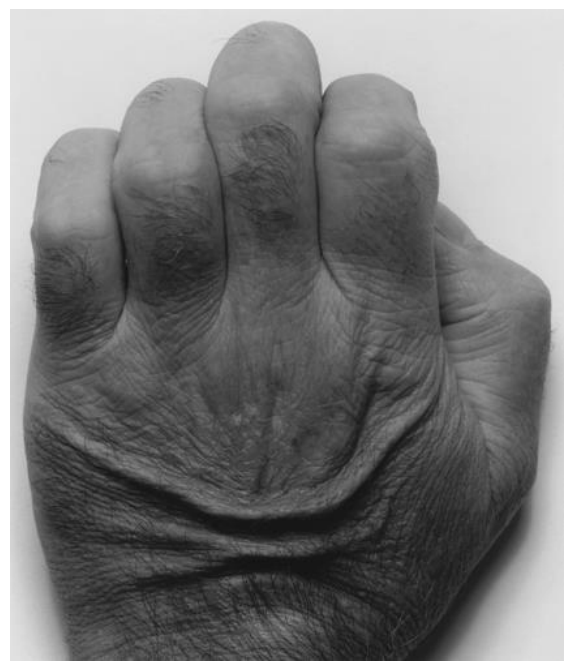

Figura 1. John Coplans, Back of Hand no 01, fotografia, 1986, 72x76cm, Yves Bresson/Musée d'Art Moderne de Saint-Étienne Métropole.

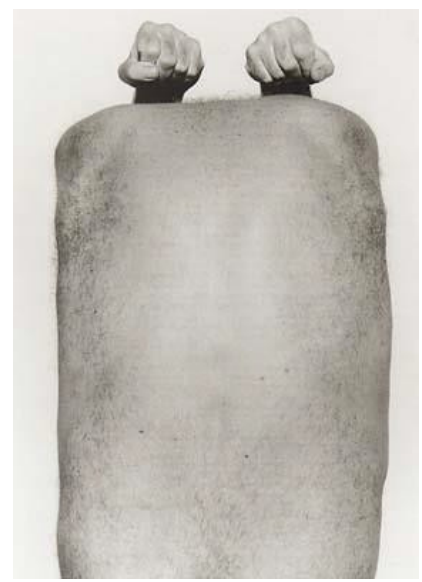

Figura 2. John Coplans, Back with Arms Above, 1984, 1213 x 935 mm, fotografia, Tate Gallery 

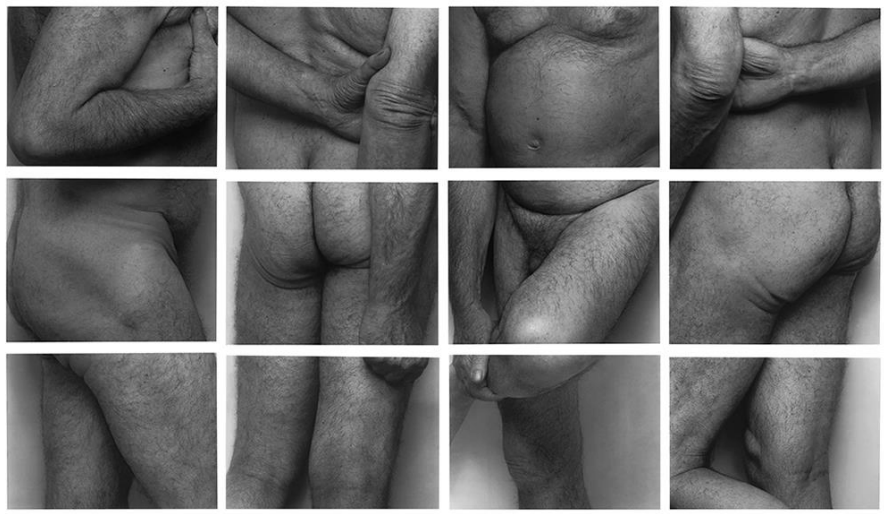

Figura 3. John Coplans, Frienze, n², 1994, 1980 x 880 mm, fotografia, Tate Gallery.

\section{REFERÊNCIAS}

BARTHES, Roland. A câmara clara. Rio de Janeiro: Editora Nova Fronteira, 1984. BRUNO, Fabiana. Imagens e reflexões da velhice in Campinas, Studium, s/d.

DAMÁSIO, António. O Sentimento de Si. Lisboa: Publicações Europa-América, 1999.

FABRIS, Annateresa. Identidades virtuais: uma leitura do retrato fotográfico. Belo Horizonte: Editora UFMG, 2004.

GIL, José. Metamorfoses do corpo. Lisboa: Relógio D’Água,1997.

MARTINÉZ, Elisa. John Coplans e um auto-retrato: abordagem semiótica da situação de exposição in Uberlândia, Uberlândia,Ouriouver, 2009.

MATESCO, Viviane. Corpo, imagem e representação. Rio de Janeiro: Zahar Editor, 2009.

(2016) “John Coplans” in MoMa Obtido em dezembro de 2016: http:// www.moma.org

------- (2016) "John Coplans" in Tate Obtido em dezembro de 2016: http:// www.tate.uk 


\title{
JOHN COPLANS: EL CUERPO ESCULTÓRICO
}

\begin{abstract}
Resumen: El artículo se refiere a la representación del cuerpo como un objeto sin identidad y simbolismo en las obras del fotógrafo John Coplans, que nos hace cuestionar la relación del autorretrato y el papel del significado del cuerpo en sus fotografías. El artista y el espectador se relacionan con el cuerpo en el imagen y la idea de un cuerpo escultórico. La base metodológica de la investigación y el estudio teórico sobre el tema, influencias, paradigmas, conceptos y referencias de autores, tales como: Viviane Matesco, Roland Barthes, Vilhem Flusser, Philipe Dubois, Annateresa Ferris entre otros; discutido a lo largo del artículo. Como resultado, se espera una contribución a los estudios de arte contemporáneo sobre la relación del cuerpo (materia) con el objeto de arte (forma) y la imagen.
\end{abstract}

Palabras clave: cuerpo; imagen; John Coplans; autorretrato.

\section{JOHN COPLANS: THE SCULPTUROUS BODY}

\begin{abstract}
This article refers to the representation of the body as an object without identity or symbolism, in the artwork of photographer John Coplans, where he questions the connection between self-portrait and the meaning of the body in his images. The artist and the public connect with the body in the image and the conception of a sculptural body The methodological basis of the research and theoretical study about the subject, influences, paradigm, concepts and references of authors such as Viviane Matesco, Roland Barthes, Vilhem Flusser, Philipe Dubois, Annateresa Ferris being discussed through the article. As a result, what is expected is a contribution to contemporary art studies about the connection between body (content) as an object of art (form) and image.
\end{abstract}

Keywords: body; image; John Coplans; self-portrait. 